\title{
RADIAL HEAD ARTHROPLASTY WITH A MODULAR PROSTHESIS - INITIAL EXPERIENCE
}

\author{
V. Petrov ${ }^{1,2}$, B. Matev ${ }^{1}$ and D. Dikov ${ }^{1}$ \\ ${ }^{1}$ 2nd Orthopedic Clinic, University Orthopedic Hospital "Prof. B. Boychev" - Sofia \\ 23rd Traumatology Department, University Hospital for Emergency Medicine "N. I. Pirogov" - Sofia
}

Summary. The Mason type III and IV radial head fractures are severe injuries that lead to decreased range of motion, alteration in the kinematics, the load transfer and the stability of the elbow. They are often in conjunction with ligament injuries, anterior or posterior joint dislocations and fractures of the coronoid process, the humeral capitulum and the olecranon. The resection of the head leads to elbow instability, late complications and arthrosis of the elbow. The open reduction and internal fixation (ORIF) in Mason type III and IV fractures is not able to restore and sustain the anatomical structure and function of the radiocapitellar joint. That is why these fractures require arthroplasty. The best results are reported with the use of metal bipolar prosthetics. We present our initial experience with radial head arthroplasty on three patients with mean follow up 18 months and a review of the English literature.

Key words: Radial head fracture, radial head arthroplasty, Mason type III and IV, modular prosthesis

he resection of the radial head has been a preferred method for treatment
of severe comminuted fractures of the radial head type III and IV ac-
cording to Mason/Johnston classification $[12,16]$, as well as progressed radiocapitellar arthrosis (Table. 1). Themedium- and long-termoutcomes of this manipulation have shown unsatisfactory results in many recent series. The resection in presence of additional lesion of the distal radioulnar ligaments, the interosseous membrane and/or some of the collateral ligaments of the elbow may lead to valgus instability, proximal migration of the radius, pain in the distal radioulnar joint and posterolateral rotational instability. Many studies present biomechanical data for the alteration in the kinematics, the load transfer and the stability of the elbow in case of radial head resection, which may cause early cartilage wear of the humeroulnar joint and secondary pain due to arthrosis $[1,3,8,10,11]$. Nowadays, the single radial head resection is acceptable only in old patients with stable ligaments and low expectation from the elbow joint. In all other cases the radial head resection must be followed by arthroplasty with metal prosthesis. 
Table 1. Mason'sclassification of the radial head fractures (Modified by Hotchkiss) [7]

\begin{tabular}{|l|l|}
\hline Type I & $\begin{array}{l}\text { Non-displaced or minimally-displaced fracture of the head or the neck of the radius } \\
\text { The rotation of the forearm (pro-supination) is restricted only by severe pain and } \\
\text { swelling without mechanical blockage } \\
\text { Joint fracture displacement < } 2 \text { mm or a fracture of the marginal edge of the head }\end{array}$ \\
\hline Type II & $\begin{array}{l}\text { Displaced }>2 \mathrm{~mm} \text { fractures of the head and neck (angulated) } \\
\text { In congruent joint or a mechanical blockage of the movements } \\
\text { Without severe comminution (possible open reduction and internal fixation) } \\
\text { The fracture include more than the marginal edge of the head }\end{array}$ \\
\hline Type III & $\begin{array}{l}\text { Severe comminution of the head and neck } \\
\text { Assessed as impossible for internal fixation on X-ray and intraoperatively } \\
\text { Requires excision for recovery of the movements }\end{array}$ \\
\hline Type IV (Johnston) & Fracture of the radial head with luxation of the elbow \\
\hline
\end{tabular}

\section{MATERIAL, METHODS AND RESULTS}

We present our initial experience with the arthroplasty of the proximal radius. In the period 2013-2015 we executed three arthroplasties on three different patients with severe comminuted Mason type III fractures of the radial head (two female and one male) (Fig. 1-4). The average age was 50 years (47-53). There were no clinical and intraoperative signs of ligament injuries. After radiological assessment of the fractures a decision for arthroplasty was taken. We used a modular cemented endoprosthesis from Co-Cr-Mo alloy (Waldemar Link \& Co, Hamburg, Germany). This prosthesis has different sizes of the components and gives the opportunity to adjust the stem and the head depending on the patient. The junction between them has an anatomical angle $7^{\circ}$. The mean follow-up period was $18(16-20)$ months postoperative. During that period the patients achieved a good range of motion and stability of the elbow. One patient had a resistant mild pain. The mean Mayo Elbow Performance Score was 85 (80-90). After that period one of the patients was lost for further follow-up.
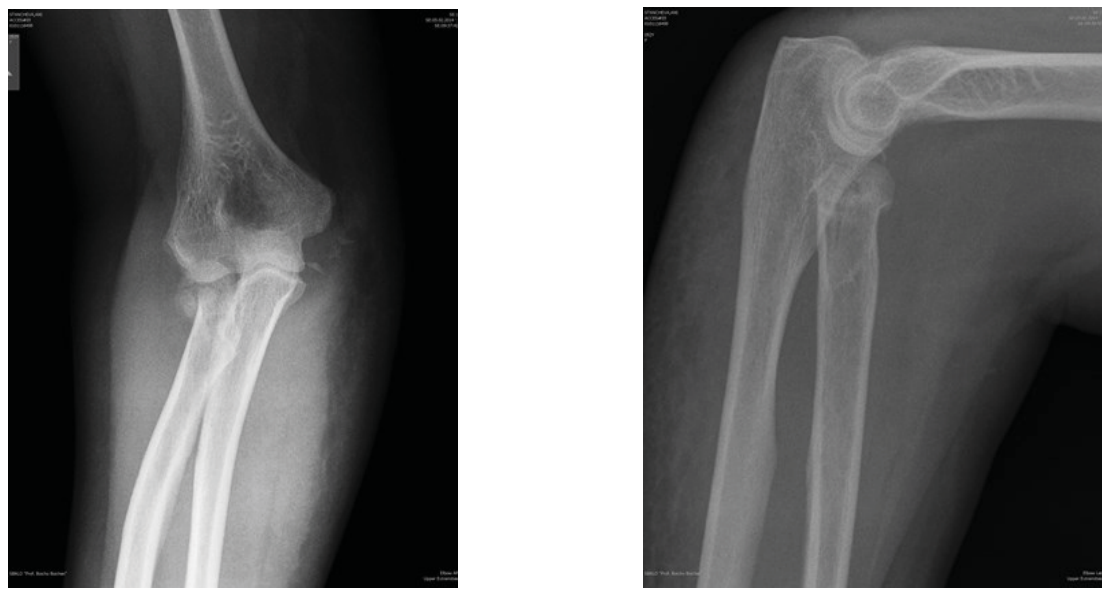

Fig. 1-2. A 50-year old woman with Mason type III fracture of the radial head without ligament injury 

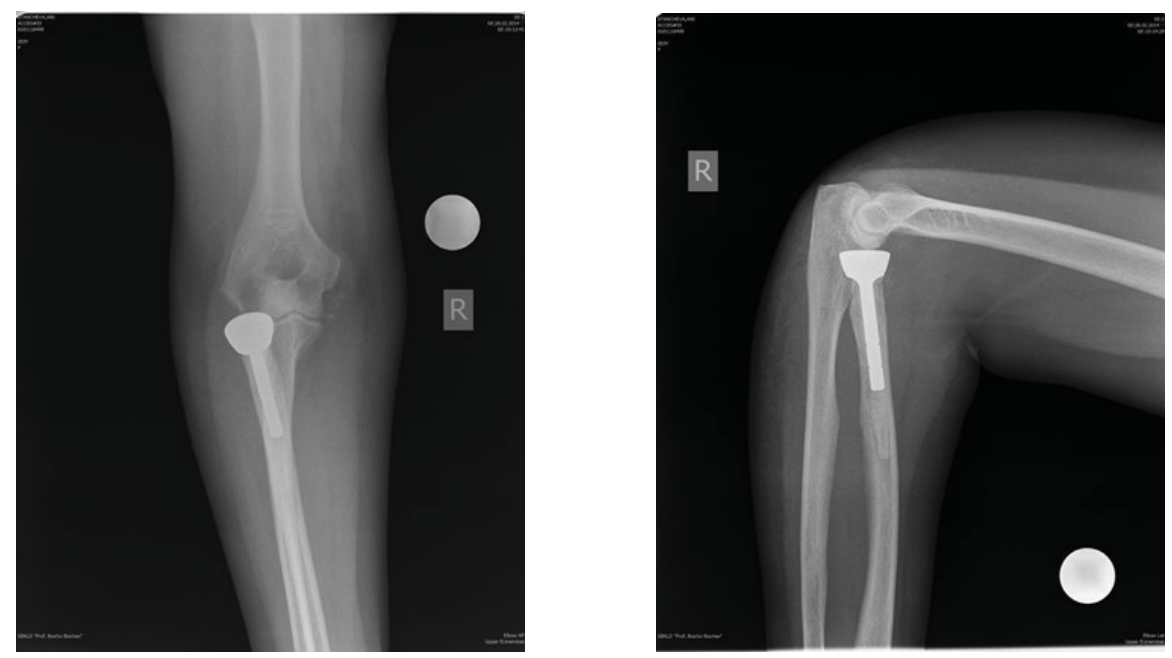

Fig. 3-4. The patient one month after arthroplasty with a modular prosthesis. She had good elbow stability, range of motion and no pain. Mayo Elbow Performance Score was 95

\section{SURGICAL TECHNIQUE}

We use the classical Kocher approach between the anconeus muscle and the radial carpal extensor muscle. This approach gives a good sight on the posterolateral surface of the radial head with the posterior interosseous nerve well protected. The good surgical technique disturbs the elbow stability quite little despite the concerns of some authors [9]. An acceptable alternative is the approach through the common digital extensor muscle that reaches the anterolateral part of the radial head. After incision of the annular ligament we use a template to determine the level of the osteotomy. The radial neck must be always resected above the radial tuberosity. With awl and files we prepare the medullar canal for the implant. After measurement of the fractured radial head, the proper size of the implant head can be determined. The height of the prosthesis fixation is very important. The implant must articulate well with the capitulum of the humerus without overstuffing, a phenomenon when the prosthesis is too long or too wide and cause pain and restriction of movement in the elbow. The too short prosthesis, on the other hand, can disturb the stability of the joint. A recent cadaver study of Riet et al. successfully proved that the lesser sigmoid notch of the ulna can be used as an indicator for the height of the prosthesis [22]. Before definite fixation, the full range of motion of the elbow must be tested. The patients can start early rehabilitation according to their ligament injuries. Between the procedures the elbow is in splint 90 o for 3 to 6 weeks. Strengthening exercises can be included after the healing of the fractures and the ligament injuries, normally between 8 and 12 weeks postoperative. For patients with complex elbow injury we recommend oral prophylaxis of the heterotopic ossification with indomethacin $25 \mathrm{mg}$ three times daily for 3 weeks. 


\section{DISCUSSION}

Hodgkiss modified the Mason classification and added a guideline for therapy of the radial head fractures [7]. He recommends conservative treatment of type I fractures, ORIF for type II and resection of the head and arthroplasty with prosthesis in type III fractures (Fig. 1). Johnston added type IV - fractures of the head with luxation of the elbow [12]. The type III and IV fractures are always complicated with severe additional lesions. In his study Ring [19] summarizes the most frequent injuries going with the radial head fracture:

- Fracture of the head with posterior elbow dislocation;

- Rupture of the medial collateral ligament or fracture of the capitulum of the humerus;

- "Terrible triad" - fracture of the radial head, fracture of the coronoid process and posterior dislocation of the elbow;

- Posterior transolecranon fracture-dislocation (posterior Monteggia);

- Fracture of the radial head and rupture of the interosseous membrane with or without distal luxation of the ulnar head (Essex-Lopresti).

The arthroplasty is a method of choice also in case of unsuccessful ORIF, severe ligament injuries leading to elbow instability, as well as in case of late complications - arthrosis of the elbow joint [23] and subluxation of the radiocapitellar joint.

There are different types of prosthesis - metal monoblock constructions, modular implants, cemented, press-fit and ingrowth stems, ceramic components. They are produced from titanium alloys, cobalt-chromium alloys, acrylic materials or silicone. The first prosthesis, made from silicone had good short-term outcome and caused an excitement among the orthopedic surgeons. Nowadays, many studies proved that they do not provide good axial and valgus stability of the elbow joint; they wear out fast and produce debris particles, leading to severe synovitis and joint lesions. On the other hand, the results with modular metal implant arthroplasty are encouraging. Moro et al. [17] described 25 cases of arthroplasty with metal monoblock prosthesis for a period of 39 months. The results were estimated as good and excellent in 17 patients, acceptable in 5 and unacceptable in 3 . The radial head prosthesis achieved good recovery of the elbow stability. Grewal et al. reported similar results in a cohort of 26 patients treated with a modular radial head prosthesis [5].

A modification of the metal prosthesis, the floating prosthesis, was created by Judet, which prosthesis allows a rotation between the head and the stem up to $35^{\circ}$ [13]. Judet et al. reported good and excellent results in 10 from 12 patients after 4-year follow up. Dozis et al. [4] had an observation over 12 patients with Judet's floating prosthesis for a mean period of 5.25 years, among them 10 patients with good and excellent results. Smets et al. [20] reported a follow up of 13 patients with type III fracture of the radial head, operated with the floating bipolar prosthesis for a mean period of 25 months. The results are estimated as good and very good in 10 patients and bad in three, as one of the prosthesis had to be removed after 8 months due to heavy decreased range of motion in the elbow. 
There are still not sufficient studies over the long-term results of the arthroplasty of the radial head with metal prosthesis in the English speaking literature. Harrington et al. [6] presented a follow up of 20 patients with metal prosthesis for a period of 12 years. There were good results in 16 patients and unsatisfactory or bad results in 4.

Interesting cadaver anthropometric study by King et al. [14] of the proximal radius demonstrated that the radial head has a mutable elliptic shape; its offset towards the radial neck may vary and its diameter correlates poorly with the diameter of the medullar canal. These results support the use of modular implants, which provide more options in size and fit better to the anatomy of every single patient. A cadaver study by Liew et at. [15] proved that regardless the size of the implants, the contact area in the radiocapitellar joint after arthroplasty decrease significantly. Even with the best fitting in size metal prosthesis the contact area decrease with $68 \%$. When the prosthesis is bigger than the radial head of the patient, the contact area gets even smaller. This creates concentration of the axial and cutting forces on a small area in the radiocapitellar joint. Nevertheless, based on the results of Harrington [6] with titan prosthesis, they determined that the decrease of the contact area is disproportionate with the wearing out of the capitellar cartilage.

The review of the English literature reveals that there is not significant difference in the results with monolite, modular or floating metal prosthesis. Pomianowski et al. [18] in a study of the elbow stability after arthroplasty of the radial head in patients with different ligament injuries proved that the Judet'sfloating prosthesis gives less stability in the joint in comparison with the other types of metal prosthesis. Two separate cases of a cartilage lesion of the capitellum as a result of arthroplasty of the radial head, both of them made with the Judet's floating prosthesis are described in the literature $[2,21]$. Despite the loss of one third of the capitellum on the X-rays, Brinkman et al. claimed that their patient was without clinical complaints. However, we consider that these two cases must provoke an increased attention to the late complications of this specific prosthesis. We think that the rotational movements in the articulation of the prosthetic head and the neck, which, on one side, provide bigger mobility in the joint, probably also cause more micro movements between the head and the capitullum and lead to accelerated osteolysis of the latter.

\section{CONCLUSION}

Our mid-term results with the radial head arthroplasty are comparable with the data in the literature. We need more long-term follow up of our cases to exclude the development of contractures, erosion of the humeral capitellum, aseptic loosening and other possible late complications, which are described in some studies. Based on our previous experience and the review of the literature, we recommend in case 
of severe comminuted radial head fracture the use of radial head resection followed by arthroplasty with a modular metal prosthesis that gives the opportunity to choose between different sizes of the head and the stem. The resection without arthroplasty is acceptable only in elderly patients with low functional requirements. We consider the Judet's floating prosthesis and the silicone prosthesis unacceptable due to the complications described in the literature. We accept the use of the lesser sigmoid notch of the ulna as an indicator for the height of the prosthesis and find it a reliable and reproducible way for the positioning of the prosthesis.

\section{REFERENCES}

1. Beingessner DM, Dunning CE, Gordon KD, et al. The effect of radial head excision and arthroplasty on elbow kinematics and stability. - J Bone Joint Surg Am 2004;86(8):1730-9.

2. Brinkman JM, Rahusen FT, de Vos MJ, Eygendaal D. Treatment of sequelae of radial head fractures with a bipolar radial head prosthesis. - Acta Orthopaedica 2005 76, № 6,867-872

3. Coleman DA, Blair WF, Shurr D. Resection of the radial head for fracture of the radial head. Longterm follow-up of seventeen cases. - J Bone Joint Surg Am 1987;69(3):385-92.

4. Dotzis A, Cochu G, Mabit $C$, et al. Comminuted fractures of the radial head treated by the Judet floating radial head prosthesis. - J Bone Joint Surg Br 2006;88(6):760-4.

5. Grewal R, MacDermid JC, Faber KJ, et al. Comminuted radial head fractures treated with a modular metallic radial head arthroplasty. Study of outcomes. - J Bone Joint Surg Am 2006;88(10):2192-200.

6. Harrington IJ, Sekyi-Otu A, Barrington TW, Evans DC, Tuli V. The functional outcome with metallic radial head implants in the treatment of unstable elbow fractures: A long-term review. $-\mathrm{J}$ Trauma 50(1): 46-52, 2001.

7. Hotchkiss RN. Displaced fractures of the radial head: internal fixation or excision? - J Am Acad Orthop Surg 1997;5:1-10.

8. Ikeda M, Oka Y. Function after early radial head resection for fracture: a retrospective evaluation of 15 patients followed for 3-18 years. - Acta Orthop Scand 2000;71(2):191-4.

9. Jackson JD, Steinmann SP. Radial head fractures. Hand Clin.2007 May;23(2):185-93

10. Janssen RP, Vegter J. Resection of the radial head after Mason type-III fractures of the elbow: follow- up at 16 to 30 years. - J Bone Joint Surg Br 1998;80(2):231-3.

11. Jensen SL, Olsen BS, Sojbjerg JO. Elbow joint kinematics after excision of the radial head. - J Shoulder Elbow Surg 1999;8(3):238-41.

12. Johnston $\mathrm{G}$ W. A follow-up of one hundred cases of fracture of the head of the radius with a review of the literature. - Ulster Med J 1962; 31: 51-6.

13. Judet T, Garreaud L, Piriou P, Charnley $G$. A floating prosthesis for radial-head fractures. - J Bone Joint Surg (Br) 1996; 78: 244-9.

14. King G, Zarzour Z, Patterson S, et al. An anthropometric study of the radial head: implications in the design of a prosthesis. - J Arthroplasty 2001;16(1):112-6.

15. Liew VS, Cooper IC, Ferreira LM, Johnston JA, King GJW. The effect of metallic radial head arthroplasty on radiocapitellar joint contact area. - Clinical Biomechaniscs 2003 18(2):115-118

16. Mason M L. Some observations on fractures of the head ofthe radius with a review of one hundred cases. - Br J Surg 1954; 42: 123-32.

17. Moro JK, Werier J, MacDermid JC, et al. Arthroplasty with a metal radial head for unreconstructible fractures of the radial head. - J Bone Joint Surg Am 2001;83(8):1201-11. 
18. Pomianowski S, Morrey BF, Neale PG, et al. Contribution of monoblock and bipolar radial head prostheses to valgus stability of the elbow. - J Bone Joint Surg Am, 2001; 83 (12): 1829-1834

19. Ring D. Displaced, unstable fractures of the radial head: fixation vs. Replacement - what is the evidence? - Injury 2008;39:1329-1337.

20. Smets S, Govaers K, Jansen N, et al. The floating radialhead prosthesis for comminuted radial headfractures: a multicentric study. - Acta Orthop Belg 2000;66(4):353-8.

21. Van Riet RP, Van Glabbeek F, Verborgt O, Gielen J. Capitellar erosion caused by a metal radial head prosthesis. A case report. - J Bone Joint Surg Am 2004;86-A(5):1061-4.

22. Van Riet RP, van Glabbeek F, de Weerdt W, Oemar J, Bortier H. Validation of the lesser sigmoid notch of the ulna as a reference point for accurate placement of a prosthesis for the head of the radius. - J Bone Joint Surg Br March 2007 89-B № 3 413-416

23. Георгиев Хр. Основи на ортопедията. Медникаров. София 2012 Камея.

$\doteq$ Corresponding author:

Dr. Viktor Petrov

Orthopedic Surgeon

3th. Traumatology Department

University Hospital for Emergency Medicine "N. I. Pirogov"

$\mathrm{Bg}-1606$ Sofia

e-mail: dr.viktor.petrov@abv.bg 